\title{
EDUCAÇÃO AMBIENTAL NAS ESCOLAS DA REGIÃO DE RIBEIRÃO PRETO (SP): CONCEPÇÕES ORIENTADORAS DA PRÁTICA DOCENTE E REFLEXÕES SOBRE A FORMAÇÃO INICIAL DE PROFESSORES DE QUÍMICA
}

\author{
Daniela Gonçalves de Abreu*, Maria Lúcia A. M. Campos e Márcia B. R. Aguilar \\ Departamento de Química, Centro de Ensino Integrado de Química, Faculdade de Filosofia, Ciências e Letras de Ribeirão \\ Preto, Universidade de São Paulo, 14040-901 Ribeirão Preto - SP, Brasil
}

Recebido em 15/12/06; aceito em 20/9/07; publicado na web em 19/3/08

\begin{abstract}
ENVIRONMENTAL EDUCATION IN SECONDARY SCHOOLS IN THE REGION OF RIBEIRÃO PRETO (SP, BRAZIL): HOW TEACHERS' VIEWS OF THE ENVIRONMENT DETERMINE THEIR TEACHING AND SOME REFLECTIONS ON CHEMISTRY TEACHERS' HIGHER EDUCATION. During short courses, 95 secondary school teachers from 49 state schools and 421 students from the Ribeirão Preto region (in Sao Paulo state, Brazil, with a population of 530,000) were asked to fill in different questionnaires. The points raised in the teacher's questionnaire were used as a guide to establish a continuous dialogue during the short courses. Most of the schools claimed to have some kind of environmental education (EE). Based on the questionnaires and dialogues we analyzed how the teachers' perceptions on EE reflect on the views secondary students hold about their own responsibility for preserving the environment. The role of universities in the preparation of chemistry teachers capable of effectively approaching EE is also discussed.
\end{abstract}

Keywords: environment; waste disposal; recycling programs.

\section{INTRODUÇÃO}

A questão ambiental está presente no cotidiano da sociedade contemporânea e tem representado um novo desafio para preservação da qualidade de vida da humanidade. A crise ambiental que o planeta vive, pela exploração indevida, e as consequiências a que estamos sujeitos, têm mobilizado vários setores da sociedade como autoridades civis, instituições governamentais e não governamentais. Esta preocupação mundial com o meio ambiente tem motivado a realização de vários encontros internacionais e locais, visando a discussão e a elaboração de propostas de soluções para o assunto. A Conferência da Organização das Nações Unidas sobre o Ambiente Humano, que ocorreu em Estocolmo em 1972, é tida como marco internacional para criação de políticas ambientais. A referida conferência marcou, a necessidade de políticas ambientais, reconhecendo a Educação Ambiental (EA) como uma necessidade para a solução dos problemas ambientais. ${ }^{1}$

No Brasil, a EA atingiu primeiro o âmbito administrativo, e só depois o sistema educativo. A oficialização da EA aconteceu por meio da lei federal de $n^{\circ} 6.938$ de 1981, que criou a Política Nacional do Meio Ambiente. ${ }^{1}$ No âmbito educativo, em 1996, foi promulgada a Lei de Diretrizes e Bases da Educação Brasileira (Lei 9.394/96), que aponta a necessidade de uma formação mais ampla do estudante da escola básica e sugere a abordagem de temas que propiciem a reflexão sobre questões como a ética, a responsabilidade e a cidadania, incluindo a percepção e compreensão do meio ambiente numa perspectiva interdisciplinar. De acordo com os Parâmetros Curriculares Nacionais, a EA deve ser desenvolvida com o objetivo de auxiliar os alunos a construírem uma consciência global das questões relativas ao meio ambiente. Ainda que em 1999 tenha sido aprovada a Política Nacional de Educação Ambiental (Lei 9.795; regulamentada pelo decreto 4.281 em 2002), que torna obrigatória a EA em todos os níveis de ensino, incluindo o ensino superior, é comum encontrar na maioria dos trabalhos sobre EA referência à escola básica.

*e-mail: danielaga@ffclrp.usp.br
Segundo levantamento realizado pelo Instituto Nacional de Estudos e Pesquisas Anísio Teixeira² (INEP) em 2002, a maioria das escolas de ensino fundamental desenvolve atividades de EA e, considerando-se o total de alunos deste nível de ensino, 71,2\% estão em escolas que trabalham de alguma forma com a temática. Com frequiência as ações de EA são reduzidas a atividades pontuais no dia do meio ambiente, do índio, da árvore, ou simples visitas a parques e reservas. ${ }^{3} \mathrm{O}$ enfoque naturalista e preservacionista de muitas das atividades, pode ser atribuído ao fato da EA ter surgido em um terreno marcado por uma tradição naturalista. ${ }^{1}$ É comum observar que as atividades de EA estão principalmente centradas nas disciplinas de Biologia e Ciências, ${ }^{4}$ enquanto que a Química é muitas vezes associada à poluição de ecossistemas, degradação ambiental e periculosidade, dentro de uma visão simplista envolvendo o tripé ambiente - química - poluição. ${ }^{5}$ Imagens como a de produtos químicos de alta toxicidade, nocivos ao meio ambiente, ou do ar cinzento de cidades poluídas, configuram o julgamento da química como "vilã".

$\mathrm{Na}$ década de 70, principalmente as disciplinas científicas foram influenciadas por um conjunto de reflexões sobre o impacto da ciência e da tecnologia na sociedade, que deu origem ao movimento Ciência-Tecnologia-Sociedade (CTS). ${ }^{6}$ Existem pontos convergentes entre o movimento CTS e a EA, uma vez que possuem como objetivo comum o desenvolvimento de uma cidadania responsável (individual e social) para lidar com problemas, que envolvam dimensões científicas e tecnológicas. Neste contexto, alguns educadores químicos brasileiros têm proposto a vinculação de aspectos sociais e ambientais ao conhecimento químico, como por exemplo, o "Projeto de Ensino de Química e Sociedade".

Apesar da existência de propostas inovadoras visando a formação cidadã, muitas não chegam às salas de aula. Segundo Schnetzler e Aragão, ${ }^{8}$ a prática docente reflete os modelos de ensino com os quais os indivíduos tiveram contato durante toda sua formação. Além disso, diferentes concepções sobre meio ambiente e EA podem influenciar a abordagem pedagógica e a adoção de estratégias pelos professores para promover a EA. Desta forma, por meio da análise das ações de 
EA propostas pelos professores pode-se conhecer quais são as concepções orientadoras da prática docente. Assim, os objetivos deste trabalho foram: identificar e analisar as ações de EA que vêm sendo promovidas nas escolas de Educação Básica de Ribeirão Preto e região, procurando conhecer as concepções sobre meio ambiente e EA que orientam a prática de professores da área de ciências da natureza; analisar em que medida estas ações atingem os objetivos básicos da EA de acordo com a classificação de Smyth; ${ }^{9}$ discutir a inserção da química para promoção da EA e, refletir sobre o papel da universidade na formação inicial dos professores de química.

\section{METODOLOGIA}

Segundo Bogdan, ${ }^{10}$ "a pesquisa qualitativa trabalha com o universo dos significados, motivos, aspirações e crenças, valores e atitudes, que corresponde a um espaço mais profundo das relações, dos processos e dos fenômenos que não podem ser reduzidos à operacionalização de variáveis". Desta forma, considerando-se o objeto de estudo deste trabalho, a metodologia utilizada apoiou-se principalmente na pesquisa qualitativa. Os instrumentos utilizados para coleta de dados foram questionários e observação participante. A observação participante, que ocorreu durante o transcorrer de todo contato com os professores, envolveu a presença física do observador, o compartilhamento de experiências de vida e o ingresso no mundo simbólico e social das pessoas. ${ }^{11}$

Desta forma, em 2004 (4 h) e 2005 (8 h), as pesquisadoras envolvidas neste trabalho participaram/ministraram uma oficina, intitulada "Meio ambiente e sociedade: a ciência que faz falta ao cidadão" dentro do programa de formação continuada de professores, "Teia do Saber", promovido pela Secretaria de Educação do Estado de São Paulo em parceria com a Faculdade de Filosofia Ciências e Letras da USP de Ribeirão Preto. As oficinas contaram com a participação de 95 professores do ensino médio da área de ciências da natureza, oriundos de 49 escolas públicas, sendo $24 \%$ da área de química, $46 \%$ de biologia, 15\% de matemática e 15\% de física.

A oficina pretendeu contribuir para reflexões sobre: um ensino de ciências naturais de forma integrada e contextualizada, possibilitando a abordagem de aspectos sócio-ambientais, em níveis local, regional e global; o desenvolvimento de aspectos científicos que fazem falta ao cidadão para compreensão dos fenômenos ambientais que vêm sendo divulgados pela mídia e, a abordagem da educação ambiental no ensino de ciências, envolvendo conhecimentos científicos, valores e tomada de decisões.

No início da oficina, os professores responderam a um questionário contendo questões objetivas e também dissertativas para identificar ações de EA desenvolvidas nas suas escolas, bem como para se conhecer a percepção que os professores tinham de si próprios como agentes responsáveis com relação ao meio ambiente. Após a devolução dos questionários respondidos, iniciou-se um diálogo, no qual todas as questões apresentadas no questionário foram retomadas e discutidas ao longo da oficina. Durante a oficina, foram feitas anotações baseadas em percepções visuais e auditivas. Propostas de ações voltadas à EA discutidas e descritas na lousa pelos professores também foram registradas em papel.

As discussões sobre as ações de EA no ambiente escolar, e a possível eficiência dessas ações para despertar a responsabilidade individual dos alunos permitiram compreender melhor o contexto dos relatos das práticas de EA nas escolas. Isto contribuiu para nortear a análise textual ${ }^{12}$ dos questionários respondidos pelos professores e, também, dos demais registros.

As atividades descritas nos questionários pelos professores, e julgadas por eles como ações de EA, foram agrupadas e classifica- das de acordo com os objetivos da EA definidos por Smyth ${ }^{9}$ e descritos por Sato, ${ }^{13,14}$ como segue: "Sensibilização Ambiental: processo de alerta, considerado como primeiro objetivo para alcançar o pensamento sistêmico da Educação Ambiental"; "Compreensão Ambiental: conhecimento dos componentes e dos mecanismos que regem o sistema natural"; "Responsabilidade Ambiental: reconhecimento do ser humano como principal protagonista para determinar e garantir a manutenção do planeta"; "Competência Ambiental: capacidade de avaliar e agir efetivamente no sistema (ambiental)"; "Cidadania Ambiental: capacidade de participar ativamente, resgatando os direitos e promovendo uma ética capaz de conciliar a natureza e sociedade".

Além do trabalho realizado com os professores de ensino médio, entre 2002 e 2005, foram ministrados mini-cursos de $6 \mathrm{~h}$ de duração para 421 alunos do ensino médio principalmente da rede pública de Ribeirão Preto e região. Estes dois grupos não são necessariamente das mesmas escolas, porém, a grande maioria faz parte da rede pública de ensino da mesma região.

Com o grupo de alunos, temas como a questão energética, poluição das águas e da atmosfera foram abordados. Organizou-se um sítio na Internet (www.usp.br/qambiental), no qual o material didático do mini-curso se encontra disponível, além de textos de apoio, jogos envolvendo questões de química, questionários, entre outros. Durante o mini-curso, foram feitos registros a partir da observação e no final do mini-curso, os alunos responderam a um questionário que, entre outras questões, pedia para eles descreverem ações individuais que poderiam colaborar para minimizar o impacto sobre meio ambiente. Realizou-se a análise textual também dos questionários respondidos pelos alunos. ${ }^{12}$

\section{RESULTADOS E DISCUSSÃO}

\section{Diagnóstico das atividades de EA e concepções orientadoras da prática docente}

Conforme definido na Conferência Intergovernamental de Tbilisi (1977), na Geórgia, a EA é um processo de reconhecimento de valores e clarificação de conceitos, objetivando o desenvolvimento das habilidades e modificando atitudes em relação ao meio, para entender e apreciar as inter-relações entre os seres humanos, suas culturas e seus meios biofísicos.

Entre os professores participantes da oficina, $73 \%$ disseram promover ações voltadas à EA nas suas escolas. No entanto, a maioria das atividades propostas engloba iniciativas individuais e pontuais, havendo poucos relatos de ações interdisciplinares. Os professores citaram em suas respostas diversas atividades:

Prof. A: Nas escolas em que trabalhei, trabalhamos em algu-
mas de forma isolada e em outras através de projetos. As ativi-
dades de educação ambiental desenvolvidas foram: a confec-
ção de panfletos feitos pelos alunos, reciclagem de lixo, visitas
ao DAERP, Departamento de Água e Esgoto de Ribeirão Preto,
a estação de tratamento de esgoto,... e outras atividades mais
como debates, cartazes, visitas a locais cheios de lixo próximo
às casas, procurando fotografar e estabelecer a consciência
nos alunos da ação como cidadão.

Todas as atividades citadas pelos professores, e julgadas por eles como ações de EA, foram agrupadas na Tabela 1 e classificadas de acordo com os objetivos da EA definidos por Smyth., ${ }^{9}$

Por meio da análise das ações de EA descritas pelos professores (Tabela 1) procurou-se conhecer concepções orientadoras da prática docente. Assim, no grupo A (4\%) foram reunidas ações que 
Tabela 1. Atividades de EA promovidas em escolas de Ribeirão Preto e região, agrupadas em categorias. O número de vezes que cada grupo de atividades foi citada está representado em termos percentuais

\begin{tabular}{ll}
\hline Grupo (\% de citações) & Atividades \\
\hline Grupo A: sensibilização (4\%) & Visitas a bosques, fazendas, matas ciliares, parques ecológicos, nascentes de água, lixões e \\
Grupo B: compreensão (57\%) & Visitas* a usinas de açúcar e álcool, a estações de tratamento de água e esgoto, a indústrias \\
& químicas. Discussões em sala de aula sobre diferença entre lixão e aterro, fazendas de \\
& compostagens, biodigestores, tempo de decomposição dos materiais, tratamento de esgoto, \\
& tipos de poluição (ar, água, solo), chuva ácida, efeito estufa, camada de ozônio, uso racional \\
& dos recursos naturais, reflorestamento, manejo sustentável, conservação da fauna e flora, \\
& Aquífero Guarani. Tratamento da água e do esgoto com atividades experimentais, aulas teóricas \\
& e práticas, trabalhos sobre reciclagem e sobre temas ambientais, vídeos, entrevistas, debates. \\
& Plantio de árvores, horta, jardinagem, fabricação de adubo e de sementeiras, reciclagem, \\
& coleta seletiva, reutilização de objetos, artesanato, verificação do desperdício de água no \\
prédio da escola, limpeza da escola e das ruas. & Apresentação de atividades em feira de ciências, passeatas para conscientização dos moradores, \\
Grupo C: responsabilidade (33\%) & teatro, paródias, poesias, cartazes, sobre água e ambiente, elaboração de panfletos pelos \\
& alunos, distribuídos à população, confecção de jornal e mural.
\end{tabular}

* Pelos diálogos com os professores, após as visitas os conceitos envolvidos eram trabalhados em classe, daí sua classificação.

evidenciam a preocupação em promover situações que coloquem o aluno em contato com a natureza e com a produção de lixo. Neste grupo identifica-se a preocupação em sensibilizar o aluno com relação à preservação do meio ambiente dentro da concepção de que a natureza é um ambiente original e "puro", no qual os seres humanos estão inseridos, ou como agentes contempladores ou como agentes poluidores. Esta concepção, também foi identificada por Tolzoni-Reis, ${ }^{15}$ em um trabalho em que investigou as concepções de professores que desenvolvem atividades de EA nos cursos de biologia, química e geografia das universidades públicas do estado de São Paulo. Neste caso, é pressuposto que os problemas ambientais e suas soluções envolvem a vontade subjetiva dos indivíduos. Busca-se sensibilizar o aluno, mostrando-lhe a quantidade de lixo descartado em aterros ou lixões. O enfoque experimental com a natureza pode permitir uma interação com a mesma de forma mais responsável.

No grupo B, estão agrupadas as atividades de EA mais citadas pelos professores $(57 \%)$ e que além de sensibilizar, objetivam auxiliar os alunos a compreenderem quais são os componentes e mecanismos que regem cada um dos sistemas abordados. Ficou evidente que a abordagem da EA na maioria das vezes é conduzida por meio de aulas discursivas:

Prof. B: "Foram dadas aulas teóricas específicas sobre os vários tipos de poluição: poluição do ar, efeito estufa, inversão térmica, camada de ozônio, monóxido de carbono e outros. Poluição da água: eutrofização e fluoração das águas, ....resíduos (Petróleo, DDT, mercúrio, etc.) .... Os assuntos citados foram colocados em debate, onde discutimos o que poderia ser feito a favor do Meio Ambiente."

Prof. C: "Foram desenvolvidas várias atividades em todas as disciplinas, utilizando textos, livros, jornais, revistas, vídeos e palestras..."

Embora as ações mencionadas demonstrem a preocupação em vincular os conhecimentos científicos aos valores e atitudes de responsabilidade sócio-ambiental, ficou evidenciado pelas estratégias, que os professores concebem que os objetivos da EA são alcançados por meio da aquisição/transmissão de conhecimentos técnico-científicos. Nesta concepção, também identificada por Tolzoni-
Reis, ${ }^{15}$ o conhecimento é considerado como mediador da relação homem-natureza. Tal concepção reflete o caráter utilitarista da relação dos sujeitos com o ambiente, ou seja, pressupõe-se que conhecimentos técnicos e científicos são necessários para interagir e "utilizar" a natureza de forma a não degradá-la.

As atividades compiladas no grupo C $(33 \%)$ revelam uma concepção de meio ambiente como sendo um recurso a ser gerenciado para assegurar sua utilização para a sociedade atual e futura. A regra dos 3R's (Reduzir, Reutilizar e Reciclar) é muito citada pelos professores. Dentro deste grupo de ações, são realizadas atividades participativas que procuram colocar o aluno como agente ativo, à medida que ele separa o lixo, produz artesanato, recicla materiais, entre outros, enquanto no grupo $\mathrm{B}$, na maioria das vezes cabe ao aluno apenas ouvir as informações selecionadas e transmitidas pelo professor. Atividades como fazer horta e jardim também foram citadas como sendo de EA, porém, acreditamos que, da maneira como foram conduzidas, contribuem mais para a socialização e valorização do indivíduo, que propriamente para a promoção da responsabilidade ambiental. Segura, ${ }^{16} \mathrm{em}$ seu trabalho sobre a EA em escolas públicas, relatou que na visão dos alunos, a horta é também uma possibilidade de melhorar a relação ensinoaprendizagem.

No grupo D (5\%) encontram-se ações que evidenciam a preocupação de envolver a comunidade na preservação do planeta, indicando a concepção do ambiente como projeto comunitário, o qual faz parte da coletividade humana. No entanto, não foi possível aprofundar com os professores o entendimento sobre a amplitude, organização e o público alvo das campanhas citadas.

\section{A responsabilidade individual e contribuições da química}

Como a região de Ribeirão Preto é um grande pólo sucroalcooleiro do país, queimar a palha da cana-de-açúcar para facilitar sua colheita é uma prática comum durante cerca de 8 meses no ano. Esta atividade foi citada por $48 \%$ dos professores, assim como o ato de respirar foi citado por $29 \%$, como formas de aumentar o efeito estufa. Este resultado evidencia a falta de conhecimento do grupo sobre o ciclo do carbono. Apesar da grande divulgação na mídia sobre o álcool como um combustível 'ecológico' e renovável, a associação entre a emissão de $\mathrm{CO}_{2}$ pela combustão da palha da cana, e a retenção deste gás durante o processo de fotossíntese não é óbvia. Respi- 
rar é visto como um ato de 'produzir' $\mathrm{CO}_{2}$, e não como o simples retorno do $\mathrm{CO}_{2}$ retirado da atmosfera pela planta que serviu de alimento para quem respira. Outro ponto evidenciado é que dificilmente os professores percebem a diferença entre a queima da palha da cana, que tem um ciclo de vida de cerca de 1 a 2 anos, com a queima de uma árvore adulta de origem amazônica, por exemplo, que levou décadas para se formar.

Apesar de todos os professores terem citado o uso de automóveis como contribuição individual para o aumento do efeito estufa, muitos apresentaram dificuldade em identificar outras ações individuais que colaboram para aumentar o efeito estufa. No entanto, estes citam com facilidade a "queima da palha da cana" (48\%), as indústrias (23\%) e o desmatamento (40\%) como grandes fontes de emissão de $\mathrm{CO}_{2}$; como se estas atividades fossem independentes de suas próprias ações. Desta forma, ficou evidenciada a falta de elo entre a indústria produtora de bens de consumo e o próprio indivíduo como consumidor deste insumo.

Com relação ao uso de veículos automotivos, a identificação individual como agente poluidor foi clara, já que $100 \%$ dos professores citaram esta ação. Porém, quando solicitados a propor ações no nível municipal para minimizar as emissões de $\mathrm{CO}_{2}$, ações como a melhoria do transporte público não foram mencionadas. Foi possível constatar que o uso de automóveis é considerado como inevitável, isto é, um problema insolúvel.

Acreditamos que a falta de experiências com EA durante os Cursos de Formação de Professores colabora para a dificuldade apresentada pelos professores em propor atividades de EA na escola que incluam a esfera individual. No entanto, foi possível constatar que os professores de biologia, que somavam $46 \%$ do grupo, tinham mais iniciativas e idéias de ações voltadas à EA que o grupo de química (24\%). A química é uma disciplina que pode ser muito útil para a compreensão do papel individual quanto à preservação ambiental, porém, muitas vezes esta disciplina se restringe a citações de problemas ambientais. Alguns exemplos do uso da química como ferramenta para a reflexão individual estão disponíveis no sítio www.usp.br/qambiental. Conceitos de entalpia de combustão podem embasar a discussão sobre a eficiência energética. Os alunos podem calcular a emissão de $\mathrm{CO}_{2}$ por botijão de gás de cozinha, ou a emissão de $\mathrm{CO}_{2}$ durante um churrasco familiar, ou ainda, sua emissão de $\mathrm{CO}_{2}$ utilizando carro ou transporte público, veículo a álcool ou à gasolina. Aproximando a gasolina pela combustão do octano, é simples estimar que um carro que roda 15 mil $\mathrm{km}$ por ano, e faz em média $12 \mathrm{~km}$ por litro de gasolina, irá emitir ao longo de um ano, aproximadamente $3 \mathrm{t}$ de $\mathrm{CO}_{2}$ para a atmosfera. Com o domínio de apenas alguns conceitos químicos, é possível estimar parcialmente a emissão anual de $\mathrm{CO}_{2}$ de cada um, permitindo a reflexão sobre a contribuição individual para o efeito estufa. Além disso, os conceitos químicos podem colaborar para contextualizar discussões de aspectos sócio-culturais envolvidos, como por exemplo, o fato de um cidadão angolano emitir $0,5 \mathrm{t}$ de $\mathrm{CO}_{2}$ por ano para a atmosfera, enquanto um brasileiro emite $1,8 \mathrm{e}$ um americano 20,1 t. $^{17}$

A temática da responsabilidade individual permeou todas as atividades desenvolvidas nos mini-cursos oferecidos por este grupo aos alunos de ensino médio (total de 421). Quando os alunos foram solicitados a avaliar se o mini-curso colaborou para sua maior reflexão sobre os problemas ambientais, 96\% afirmam que sim. A maio-ria dos alunos (97\%) disse que está disposta a colaborar na preservação do meio ambiente, no entanto, ao exemplificar as atitudes que pretendem tomar para atingir tal objetivo, $31 \%$ das ações propostas (de um total de 989) envolveram o fato de não jogar o lixo em lugares impróprios (101 citações) e sua reciclagem (205 citações). Abaixo encontram-se alguns dos discursos mais comuns:

\section{"Jogar lixo no lixo" "Não jogar lixo na rua" "Não jogar lixo em lugares inadequados" "Reciclar meu lixo" "Separar os lixos recicláveis"}

Muitos alunos acreditam que não jogar lixo no chão ou em lugares inadequados representa uma importante contribuição na preservação da natureza. Apenas $8 \%$ das ações propostas abrangeram a diminuição no consumo de produtos industrializados como forma de reduzir o lixo gerado. Algumas citações feitas pelos alunos foram:

\section{"Diminuir a quantidade de lixo que eu produzo" "Diminuir o consumo de alimentos que contenham muitas embalagens" \\ "Pegar menos sacolinhas no mercado"}

Foi possível constatar pela análise do questionário e diálogo com os professores que a discussão de problemas ambientais na escola, muitas vezes, se reduz à abordagem sobre a disposição do lixo em lugares apropriados e reciclagem, sendo coerente com as respostas dos alunos $(31 \%)$. Entendemos que as ações que visam manter a limpeza de locais públicos são ações principalmente voltadas à responsabilidade social e cidadã, envolvendo o respeito à coletividade. A contribuição destas ações para a EA irá depender de como estas serão conduzidas. Consideramos como atividades que envolvem a EA aquelas em que o indivíduo compreende sua contribuição dentro do ecossistema em que vive, e atua, por exemplo, economizando recursos energéticos e naturais, visando minimizar seu impacto no meio ambiente. Concordamos com Travassos,${ }^{18}$ que o papel da escola não se reduz a incentivar a coleta seletiva de lixo, em seus espaços ou em locais públicos, para que seja reciclado posteriormente. É necessário também questionar os valores ligados aos bens de consumo da sociedade, que resultam numa produção de lixo cada vez mais elevada.

\section{Reflexões sobre a dimensão ambiental na formação docente em Química}

A universidade como formadora de professores tem a responsabilidade de inserir a dimensão ambiental nos currículos dos cursos de licenciatura. De acordo com Sorrentino, ${ }^{19} \mathrm{em}$ um estudo de caso realizado junto à Escola Superior de Agricultura "Luiz de Queiroz", da USP, as ações mais comuns adotadas por algumas universidades têm sido a incorporação de disciplinas, geralmente optativas no caso das chamadas carreiras técnicas, ou criação de comissões interdepartamentais, que tenham como objetivo a promoção da educação ambiental na universidade. Porém, apesar destas iniciativas, de acordo com o Programa Parâmetros em Ação Meio Ambiente na Escola, ${ }^{20}$ da Secretaria de Educação Fundamental, "os currículos dos cursos de formação inicial de professores e programas de formação continuada não têm efetivamente garantido o preparo necessário para o exercício adequado das atividades profissionais com relação à promoção da EA".

Embora professores de diferentes áreas das ciências da natureza tenham sido envolvidos neste trabalho, acreditamos que seja pertinente fazer algumas reflexões mais específicas sobre os Cursos de Química (Bacharelado e Licenciatura). Para estes cursos, as Diretrizes Curriculares Nacionais, elaboradas em atendimento à Lei de Diretrizes e Bases da Educação Nacional (9394/96) e ao Edital 04/97 da Secretaria da Educação Superior do MEC, estabelecem que além da formação didática, científica e tecnológica só- 
lida do profissional, deve também ser garantida uma formação humanística que dê condições ao egresso de exercer a profissão em defesa da vida, do ambiente e do bem-estar dos cidadãos. Com relação às competências e habilidades dos profissionais da referida área, afirmam que estes necessitam ser preparados para compreender e avaliar criticamente os aspectos sociais, tecnológicos, ambientais, políticos e éticos, relacionados às aplicações da Química na sociedade. O profissional em química também deverá ser capaz de avaliar criticamente a aplicação do conhecimento em Química, tendo em vista o diagnóstico e o equacionamento de questões sociais e ambientais. ${ }^{21,22}$

No final da década de 90, no Brasil, se iniciou uma discussão na comunidade química sobre o papel da universidade não apenas como formadora de profissionais, mas também como geradora de resíduos. ${ }^{23}$ Em 2000 e 2001, a Sociedade Brasileira de Química promoveu durante a $23^{\mathrm{a}}$ e a $24^{\mathrm{a}}$ Reunião Anual oficinas sobre "Gerenciamento e Tratamento de resíduos químicos". De certa forma, a discussão sobre a responsabilidade da universidade na geração, tratamento e descarte de resíduos químicos influenciou a incorporação da dimensão ambiental em Cursos de Graduação em Química. ${ }^{23,24}$ A partir daí, algumas instituições inseriram a preocupação com o meio ambiente em seus cursos, implementando programas de gerenciamento, minimização e adequada destinação de seus resíduos. ${ }^{25-27}$ Por exemplo, o Campus da USP de Ribeirão Preto, em 2001, instituiu um Programa de Gerenciamento de Resíduos. Além disso, algumas disciplinas, como por exemplo, a Química Analítica Qualitativa, do Departamento de Química da FFCLRP/USP-Ribeirão Preto, revisou seu programa, com o intuito de eliminar excessos, etapas repetitivas, e incluir discussões sobre toxicidade e tratamento de alguns resíduos. ${ }^{27} \mathrm{Na}$ mesma época, instituíram-se também disciplinas como "Tratamento de Resíduos Químicos", "Noções de Segurança" e "Química Ambiental", entre outras, que procuram despertar nos alunos a responsabilidade individual com relação ao meio ambiente.

Todavia, acreditamos que a abordagem de questões ambientais, de forma estanque, em disciplinas isoladas é insuficiente para formar profissionais, principalmente professores, que possam propor ações de EA de forma mais efetiva nas escolas. Além disso, de acordo com o inciso I do Capítulo II, § 3, da lei no. 9795, de 27 de abril de 1999, o desenvolvimento de instrumentos e metodologias que visem a incorporação da dimensão ambiental, nos diferentes níveis de ensino, deve ocorrer de forma interdisciplinar.

Acreditamos que promover discussões em diversas disciplinas de química durante o curso de graduação, relacionando aspectos sociais, culturais e econômicos, como relatado por Moradillo e $\mathrm{Oki}^{5}$ para a disciplina de Química Geral, represente um desafio a ser abraçado na formação do professor de química. Porém, os meios para que isto aconteça, são objeto de amplas e profundas discussões no âmbito da Universidade. Talvez, uma possível estratégia inicial pudesse ser o envolvimento de profissionais de áreas como ciências humanas e sociais que, em determinados momentos dos Cursos de Licenciatura, pudessem discutir os temas ambientais sob o ponto de vista da sua área de atuação.

É importante salientar que, embora estas reflexões enfatizem os cursos de Química, compreendemos que a EA é mais que o ensino de ciências, pois tem como objetivo a mudança de atitudes para que o indivíduo atue de forma responsável com relação ao meio ambiente. Acreditamos que a Química possa contribuir para a promoção da educação ambiental, no sentido de fazer com que as pessoas compreendam os problemas ambientais e reflitam sobre as suas contribuições individuais. No entanto, considerando o meio ambiente como um campo de interações entre cultura, sociedade e base física e biológica dos processos vitais, no qual todos os termos desta relação se modificam dinâmica e mutuamente, ${ }^{1}$ reco- nhecemos que o somente o conhecimento químico não é suficiente para modificar a intervenção do homem no meio ambiente.

\section{CONSIDERAÇÕES FINAIS}

Foi possível constatar que várias atividades visando a EA são promovidas nas escolas de educação básica de Ribeirão Preto e região, concordantes com dados relatados pelo INEP. No entanto, muitas destas atividades são realizadas de forma pontual e disciplinar, além de focar na compreensão de problemas ambientais por meio de aulas e discussões teóricas. Pelos questionários e diálogos com os professores foi possível notar que, com exceção da reciclagem do lixo, foi grande a dificuldade de se elaborar propostas e atividades de EA capazes de atingir a responsabilidade individual. Acreditamos que tal fato possa ser um reflexo da inadequada formação inicial do professor que, por sua vez, é refletida nas respostas dos alunos.

Observou-se uma maior articulação dos professores de biologia, quando comparados com os de química, no que diz respeito às ações de EA promovidas nas escolas. A química parece ser uma disciplina desperdiçada nas atividades de EA na escola básica. Conceitos simples como estequiometria de reação, entre outros, já podem dar subsídios para se discutir sobre a responsabilidade individual. No entanto, para que haja uma mudança neste quadro é preciso que a formação dos professores de química caminhe neste sentido. Acreditamos que a abordagem da problemática ambiental em diversas disciplinas do Curso de Licenciatura em Química, e não somente em algumas disciplinas estanques, e ainda, incluindo aspectos sociais, culturais, éticos e econômicos, representa um desafio a ser superado na formação do professor.

Apesar deste trabalho apresentar reflexões acerca da formação de professores, entendemos que a promoção de atividades visando a EA na escola básica não seja dependente exclusivamente da formação do professor. É imprescindível que as escolas ofereçam infraestrutura e apoio administrativo para realização das atividades. Acreditamos que os dados e idéias expostas neste trabalho possam servir de subsídios para discussões acerca dos currículos dos Cursos de Licenciatura em Química.

\section{AGRADECIMENTOS}

Aos organizadores do Programa Teia do Saber (Motokani, M.T.; Matos, M.S.; Kawasaki, C.S.) na Faculdade de Filosofia, Ciências e Letras de Ribeirão Preto e aos professores participantes dos anos de 2004 e 2005. Agradecemos também à Coordenadoria de Assistência Social da USP pelas bolsas concedidas, à Casa da Ciência Galileu Galilei, do Município de Ribeirão Preto, pela disponibilidade de espaço físico para realização dos mini-cursos oferecidos aos estudantes, e à graduanda R. Neres pela contribuição na organização dos mini-cursos e apoio na coleta inicial dos dados.

\section{REFERÊNCIAS}

1. Carvalho, I. C. M.; Educação Ambiental: a formação do sujeito ecológico, Cortez: São Paulo, 2004.

2. http://www.inep.gov.br/imprensa/noticias/censo/escolar/news02_05.htm, acessada em Maio 2007.

3. Obara, A. T.; Silveira, M. P.; Kiouranis, N. M. M.; http://ensciencias.uab.es/ webblues/www/congres2005/material/comuni_orales/1_ense_ciencias/1_2/ obara_453.pdf, acessada em Outubro 2006.

4. Dias, G. F.; Educação Ambiental - princípios e práticas, Gaia: São Paulo, 1993.

5. Moradillo, E. F.; Oki, M. C. M.; Quim. Nova. 2004, 27, 332.

6. Santos, W. L. P.; Schnetzler, R. P.; Educação em Química: compromisso com a cidadania, $2^{\mathrm{a}}$. ed., Ed. Unijuí: Ijuí, 2000.

7. Santos, W. L. P.; Mól, G. S.; Química e Sociedade- Projeto de Ensino de Química, Nova Geração: São Paulo, 2005. 
8. Schnetzler, R. P. Em Ensino de Ciências: fundamentos e abordagens; Schnetzler, R. P.; Aragão, R. M. A., orgs.; Vieira Gráfica/(UNIMEP/ CAPES): Campinas, 2000.

9. Smyth, J. C.; Environ. Educ. Res. 1995, 1, 3.

10. Bogdan, R.; Biklen, S.; Investigação Qualitativa em Educação, Ed. Porto: Portugal, 1994.

11. Flick, U.; Uma Introdução à Pesquisa Qualitativa, 2a . ed., Bookman:Porto Alegre, 2004.

12. Moraes, R. Em Metodologias Emergentes de Pesquisa em Educação Ambiental; Galiazzi, M. C.; Freitas, J. V., orgs.;Eds. Unijuí: Ijuí, 2005, cap.3.

13. Sato, M.; Tese de Doutorado, Universidade Federal de São Carlos, Brasil 1997.

14. Sato, M.; Educação Ambiental, Rima: São Carlos, 2003.

15. Tolzoni-Reis, M. F. de C.; Educação Ambiental - natureza, razão e história, Autores Associados: Campinas, 2004.

16. Segura, D. de S. B.; Educação ambiental na escola pública - da curiosidade ingênua à consciência crítica, Annablume/FAPESP: São Paulo, 2001.

17. http://unstats.un.org/UNSD, acessada em Outubro 2006.

18. Travassos, E. G.; A prática da educação ambiental nas escolas, Meditação: Porto Alegre, 2006.
19. Sorrentino, M.; Tese de Doutorado, Universidade de São Paulo, Brasil, 1995.

20. Ministério da Educação - Secretaria de Educação Fundamental.; Programa Parâmetros em Ação - Meio Ambiente na Escola, Caderno de Apresentação, 2001.

21. Andrade, J. B.; Cadore, S.; Vieira, P. C.; Zucco, C.; Pinto, A. C.; Quim Nova 2004, 27, 358.

22. Andrade, J. B.; Pinto, A. C.; Cadores, S.; Vieira, P. C.; Zucco, C.; Pardini, V. L.; Curi, L. R. L.; Quim. Nova 2005, 28 Suplemento, S7.

23. Micaroni, R. C. Tese de Doutorado, Universidade Estadual de Campinas, Brasil, 2001

24. Abreu, D. G.; Tese de Doutorado, Universidade de São Paulo, Brasil, 2003.

25. Amaral, S.; Machado, S. T.; Peralha, M. C. R; Câmara, M. R.; Santos, T. Berleze, L., Falcão, H. L.; Matinelli, M.; Gonçalves, R.; Oliveira, E. R.; Brasil, J.; Araújo, M. A.; Borges, A. C. A.; Quim. Nova 2001, 24, 419.

26. Cunha, C. J.; Quim. Nova 2001, 24, 424.

27. Abreu, D. G.; Costa, C. R.; Assis, M. D.; Iamamoto, Y.; Quim. Nova 2006, $29,1381$. 